\title{
Circuit
}

Musiques contemporaines

\section{Transcultural Music-Making in Contemporary Music Ensembles: Five Approaches in Germany, the Netherlands, Uzbekistan and Turkey}

\section{La pratique musicale transculturelle des ensembles de musique contemporaine : cinq approches en Allemagne, aux Pays-Bas, en Ouzbékistan et en Turquie}

\section{Katja Heldt}

Volume 28, numéro 1, 2018

De nouvelles racines pour une musique nouvelle ? Perspectives transtraditionnelles et transculturelles

URI : https://id.erudit.org/iderudit/1044375ar

DOI : https://doi.org/10.7202/1044375ar

Aller au sommaire du numéro

Éditeur(s)

Circuit, musiques contemporaines

ISSN

1183-1693 (imprimé)

1488-9692 (numérique)

Découvrir la revue

Citer cet article

Heldt, K. (2018). Transcultural Music-Making in Contemporary Music

Ensembles: Five Approaches in Germany, the Netherlands, Uzbekistan and

Turkey. Circuit, 28(1), 45-57. https://doi.org/10.7202/1044375ar

\section{Résumé de l'article}

Cet article décrit les approches de cinq ensembles spécialisés dans les pratiques musicales transculturelles en Allemagne, aux Pays-Bas, en Ouzbékistan et en Turquie. Tout en rencontrant des défis conceptuels et pratiques similaires dans le processus de combinaison de traditions musicales et de contextes culturels différents - par exemple, la question de la fusion entre les traditions orales et écrites, les systèmes d'accord ou les perceptions musicales, et les modes de présentation - chaque ensemble propose diverses stratégies pour les mettre en oeuvre, tout dépendant de leurs dispositions politiques, historiques et géographiques.

Ce texte examine les façons dont la musique dérive de fonctions représentationnelles dans le cadre de processus d'affiliation, de délimitation, de représentation et de construction identitaire. 


\section{Transcultural Music-Making in Contemporary Music Ensembles: Five Approaches in Germany, the Netherlands, Uzbekistan and Turkey}

Katja Heldt

Marked by globalization and hybridization processes and by the constant global flow of ideas, arts and people, the coexistence of traditions as well as the ubiquitous access and mutual influences of musical genres, traditions and styles, the current era paves the way for musical encounters and collaborations that result in the expansion of the field of musical creation and perception and offer strong creative scope for interweaving musical inspirations.

The present article focuses on the question of how ensemble formations combine musical traditions in favor of the expansion of new sounds in the context of Western contemporary classical music, which stands out as being innovative and continuously searching out new sonic material, rare instrumentation, exceptional timbres and sophisticated playing techniques. By means of examining five examples of transcultural ${ }^{1}$ ensembles for contemporary music - namely Ensemble Windstreken ${ }^{2}$ and Atlas Ensemble ${ }^{3}$ from the Netherlands, Asian Art Ensemble from Germany, Omnibus Ensemble ${ }^{5}$ from Uzbekistan and Hezarfen Ensemble ${ }^{6}$ from Turkey - which cover a broad geographical spectrum within Europe, Turkey and Central Asia and expose different approaches of combining musical elements and instruments from diverse traditions, this article addresses questions of how their merging is utilized to expand the sonic repertoire, while simultaneously being used as a tool of affiliation or delimitation within the scene of contemporary music.

The issues and risks of how music's ability to represent and construct different cultural and social identities, of how musical-aesthetic discourses

\footnotetext{
1. The term transculturalism, despite its various definitions and controversial contemplation in different sociological strands, is being used to describe the combination of elements of more than one culture to delineate concepts of multi- or interculturality.

2. https://windstreken.wordpress.com (consulted on October 30, 2017).

3. www.atlasensemble.nl/ ensemblemembers.html (consulted on October 30, 2017).
}

4. www.asianart-ensemble.com (consulted on October 30, 2017).

5. www.omnibus-ensemble.asia (consulted on October 30, 2017).

6. www.hezarfenensemble.com (consulted on October 30, 2017). 
7. Born and Hesmondhalgh, 2000, p. 2.

8. See Bohlman, 2007, Cook 2013, Utz, 2013 and 2014.

9. See Taylor, 2007.

10. See for example Stokes, 1994 : Frith, 1996; Biddle and Knights, 2007; Hall and Du Gay 2011.

11. See El-Ghadban, 2009.

12. See Nettl, 1998; Corbett, 2000, Bhagwati, 2013; Bayley and Dutrio, 2016; Östersjö and Nguyễn, 2017. are inherent in the notion of representing or appropriating another music or culture and whether concepts of contemporary music-making are able to overcome the alterity between traditions have been broadly discussed in the discourse literature. In their detailed introduction to the seminal work Western Music and Its Others, Georgina Born and David Hesmondhalgh offer a detailed overview on the inflections "of musical borrowings and appropriations, and the way that music has been used to construct, evoke, or mark alterity of a musical or a sociocultural kind." Scholarship in postcolonial studies has offered several attempts at deconstructing the history of world music, ${ }^{8}$ and has described the way music has been used to manifest forms of othering, exoticisms and orientalisms. ${ }^{9}$ Furthermore, authors like Stuart Hall, Martin Stokes, Ian Biddle and Simon Frith ${ }^{10}$ have studied the way music functions in the construction of identity. One particular study that adopts this approach is presented by Yara El Ghadban and her analysis of international competitions and the difficulties and burdens of a single composer being seen as representative of a whole culture or nation. ${ }^{11}$ Another focus is offered by theoretical approaches towards composition methods combining diverse musical traditions, frequently using improvisations as a means of transcultural communication..$^{12}$

For this article and based on interviews with the artistic directors, the five ensembles are questioned about internal musical structure and means of sound creation, aesthetics, composition strategies and the underlying problems. While the approaches differ in their practical, theoretical and geographical contexts, all ensembles face several similar obstacles, such as how to combine culturally different concepts, aesthetics, tuning systems, playing techniques and ways of conceiving music, and the extent to which it is legitimate to use the source of sound regardless of its cultural background. Furthermore, another challenge concerns how to construct hierarchical or collective structures of artistic decision-making and whether those aspirations help in overcoming alterity between traditions. Four of the five presented ensembles adopt educational strategies in the form of annual academies, research projects, composer workshops or virtual guides with audiovisual explanatory material to offer an insight into the traditions with which they are dealing and provide new sources of sonic innovation.

\section{Windstreken Ensemble (Leiden, the Netherlands)}

The Windstreken Ensemble from Leiden in the Netherlands was formed in 2004 by flutist, saxophonist and composer Piet de Mast, whose interest in combining music from different traditions began with his attempts at impro- 
vising with church organs and flute and elaborated over time by integrating other professional musicians ${ }^{13}$ living in Leiden and specialized in different traditions, ranging from early to contemporary Western classical music, jazz, improvisations, music from India and Arabic cultures into one unique ensemble structure. Based on the members' broad musical interests, the ensembles' repertoire entails - aside from a few arrangements of European early music - uniquely composed pieces by Piet de Mast, the ensemble member and Oud-player Kamal Hors from Morocco, and Dutch composer Leonard Evers, who has attended the rehearsals from the beginning and knows all the musicians personally. Within their composition concepts, the composers take into account all individual capacities, interests and musical backgrounds. Confronted with the difficulties of intermingling distinct traditions such as diverse ways of musical perception and notational systems, the composers are challenged to invent compositional strategies shifting between improvisation and composition to circumvent these differences:

Generally all of us incorporate improvisations into the framework of each composition, in order to give space for the musicians to participate with their own musical language. Leonard Evers writes clear arrangements with detailed notations, whereas Kamal Hors, who is not trained in reading Western notation, provides moreover a musical structure as a base for improvisations. My own compositions can be described as a work in progress and usually start out of a melody or harmony that I find while playing the piano with the specifics of each musician in mind. Those notated fragments are being tested by the musicians and rearranged until we are collectively satisfied with the results. The final notation depends on each musician's capacity of reading notes and sometimes includes even simple midi-files or verbal explanations providing all necessary information for the piece. ${ }^{14}$

The ensemble focuses on combining music from different geographical regions, epochs and genres equally and collectively deciding on the common ground of their aesthetic direction. Windstreken uses the transcultural approach primarily in order to expand their sonic repertoire and musical perception.

\section{Asian Art Ensemble, Berlin, Germany}

The Asian Art Ensemble is based in Berlin, Germany, and was initiated in 2007 by the composer, guitarist and percussionist Il-Ryun Chung, shengplayer Wu Wei and double bass-player Matthias Bauer. With its instrumentation ranging from Western string instruments to traditional instruments from China, Japan and Korea, ${ }^{15}$ the ensemble aims to unify the sonic worlds from three diverse Asian traditions and Western contemporary music. The
13. Pieter de Mast, the Netherlands (soprano saxophone \& flutes), Sebastiaan van Delft, the Netherlands (organ), Kamal Hors, born in Morocco, living in the Netherlands, (oud \& voice), Jörg Brinkmann, Germany (cello), Udo Demandt, the Netherlands (percussion), Nicole Jordan, born in Canada, living in the Netherlands (voice), Leonard Evers, the Netherlands (composition), https://windstreken. wordpress.com (consulted October 30, 2017).

14. Piet de Mast interviewed by the author via Skype on December 5, 2016.

15. Wu Wei (sheng) originally from China, based in Berlin since 1995, Hong Yoo, (daegeum), Youjin Sung (gayageum), II-Ryun Chung (janggu/ gongs), all three living in Berlin with South-Korean background, Matthias Leupold (violin) from Germany, ChangYun Yoo (viola) from South-Korea, Naoko Kikuchi (koto) born in Japan, Gabriella Strümpel (cello) born in the US and Matthias Bauer (double bass) from Germany. 
16. II-Ryun Chung interviewed by the author via Skype on May 13, 2017 ensemble's mission is to reveal new paths of sound creation beyond existing composition languages and techniques, while focusing on the origins of the instruments and offering an insight into similarities and differences in the apparatus of the other instruments.

The advantage of such an ensemble is the possibility to join instruments with a long tradition and historic background. The development of the instruments can be seen as witnesses of cultural and historical processes that can be traced back for centuries. Some of the Asian instruments even have the same origins and developed in different directions and geographical spheres. We try to rediscover and modulate inherent sound qualities and overcome the restrictions of some of the highly complex musical idioms. ${ }^{16}$

Being located in Berlin and geographically distant from existing political tensions in some Asian regions gives ground for musical encounters and experimentation that otherwise would not necessarily be possible.

The formation of a transcultural ensemble requires overcoming challenges on many levels. The initial phase of our ensemble was based on musical improvisations, mutual listening, understanding of rhythmical structures and tuning systems and the exploration of the sonic possibilities of our instruments. In addition to this, we realized, that the levels of our internal communication were not intuitive and even though we all read occidental notation, we had to get used to other cultural codes, such as giving cues through corporal gestures like breathing, or nodding. ${ }^{17}$

In order to play contemporary music and given the lack of suitable repertoires, the ensemble commissions pieces and invites interested composers to attend two-day-long workshops during which the instrumentalists demonstrate the techniques and the sonorities of their instruments, while also motivating the composers to get involved with the cultural and historical background of the instruments and explore the compositional possibilities beyond their usual musical language. As Chung states, "most of the commissioned composers, even those coming from Asian countries, have an education in Western classic tradition and write fully notated pieces, only in few cases do we use graphical notation or conceptual scores for selected improvisation."18

One of the main problems of transcultural music-making described by Il-Ryun Chung is the limited time during workshops and the designated composition phases to become deeply involved with the instruments:

The composers don't always reach the necessary level to incorporate the real beauty of the instruments, because each instrument would require a long and intense preparation and engagement with the culture. We also observe a certain hesitation confronting the idiomatic possessions of the instruments. Some composers fear to sound too Chinese, Japanese or Korean and therefore neglect some 
interesting paths. With our ensemble, we offer them a platform and encourage them to reach out for new paths and sounds. ${ }^{19}$

With its approach, the Asian Art Ensemble seeks to broaden the repertoire of Western contemporary music by searching for new sonorities of traditional instruments from Asian cultures, beyond existing musical idioms. Being located in a city with a wide new music scene, the use of Asian sounds provides a certain sonic autonomy and conceptual demarcation towards other new music formations.

\section{Atlas Ensemble (Amsterdam, the Netherlands)}

The Atlas ensemble is situated in the Netherlands and with its approach of combining different musical traditions and local instruments from various cultures with Western contemporary classical music into a single ensemble, it offers various reflections on concepts of globalization. Founded in 2002 by Joël Bons, composer and artistic director of the Nieuw Ensemble, Atlas Ensemble annually reassembles professional musicians ${ }^{20}$ residing in China, Central Asia, the Near East and Europe for project-based rehearsals and concert phases. According to Bons, the central objective of the ensemble is to connect musicians, enhance the mutual influences and inspirations of different art music traditions and the creation of a new orchestration, the elaboration of a new intertraditional repertoire mirroring the circumstances of globalized societies with its parallel existing traditions. The periodic encounter of musicians, composers and scholars offers the possibility to enlarge the general knowledge on properties and techniques of a broad scope of instruments from around the world, as well as to foster an understanding of their similarities and differences. During the process of its cultural interconnection, the ensemble also focuses on aspects of transculturalism, namely the confrontation and reunification of instruments originating from the same families and ancestors, which developed through travels over the course of the centuries. Therefore, the main purpose is a cross-pollination of traditions and achievements of the art music of different cultures.

Just as our society has been irrevocably transformed into a multicultural community, the music world is also in constant flux. The musical landscape of the future will be determined by ensemble formations that unite disparate musical cultures, stylistically - in terms of idiom - as well as in terms of instrumental heritage. ${ }^{21}$

As Bons further states, the processes of intertwining musical cultures in globalized societies risk the abolition of traditions towards a universal culture, but hence cultural exchanges can also protect and respect musical traditions and enable processes of hybridization:
20. The musicians of Atlas Ensemble in 2016 are: Harrie Starreveld, the Netherlands (shakuhachi/ flute), Gevorg Dabaghian, Armenia (duduk/ zurna), Raphaela Danksagmüller, Austria (duduk/recorder), Ernest Rombout, the Netherlands (musette/ oboe/ English horn), Anna voor de Wind, the Netherlands (clarinette), Wu Wei, born in China, living in Germany (sheng), Hua Yifei, China (sheng), Naomi Sato, born in Japan, currently living in the Netherlands (sho), Lan Weiwei, China (pipa), Kiya Tabassian born in Iran and living in Canada (setar), Elchin Nagijev, Azerbaijan (tar), Bassem Alkhouri, born in Syria, living in Germany (qanun), Nieder Goto, born in Japan, living in the Netherlands (koto), Ding Xueer, China (zheng), Ernestine Stoop, the Netherlands (harp), Yang Xue, China (erhu), Dhruba Ghosh, India (sarangi), Elshan Mansurov, Azerbaijdan (kamancha), Neva Özgen, Turkey (kemençhe), Dario Calderone, born in Italy, living in the Netherlands (double blass), http://www.atlasensemble.nl/ ensemblemembers.html (consulted on October 30, 2017).

21. Atlas Ensemble mission statement: http://www.atlasensemble.nl/mission. html (consulted on October 30, 2017). 
22. Documentation on Atlas Ensemble on YouTube https://www.youtube.com/ watch?v=iQf6QXoka2l\&list=UUCrMg rcW-OtrRWXfwoRrSxg\&index $=2 \&$ fea ture $=$ plcp (consulted on October 30 , 2017).

23. Atlas Ensemble mission statement: http://www.atlasensemble.nl/mission. html (consulted on October 30, 2017).

24. Atlas Lab information page: http:// www.atlasensemble.nl/for-composers. html (consulted on October 30, 2017).
The big danger of globalization is, that everything becomes the same. But if you value and caress the differences and at the same time you are researching what is in common and what are the possibilities between all the differences and all that you have in common, then for creative people it's a goldmine. ${ }^{22}$

In order to engage with the obstacles and complexities of combining musical traditions, the Atlas Ensemble commissions pieces and encourages composers to dedicate themselves to the work on questions such as how to combine different concepts of oral and improvisational traditions on the one hand and notational and composition traditions on the other, as well as how to include different aesthetics, techniques, tuning systems, tonalities and ways of musical perception without opposing Eurocentristic perspectives. As stated in their mission statement, the ensemble addresses general moral inhibitions:

Is it legitimate, for example, to regard a local instrument purely as a source of sound, independently of its cultural background, or is this a naïve or even flawed approach? How can a composer take full advantage of the virtuosity and spontaneity of a master of the tar, kemancha or kanun, while the player can hardly read music? How does he deal with the various tuning and tonal systems; which one should be applied? ${ }^{23}$

In favor of finding answers to these requirements collectively, since 2009, the Atlas Lab has been established as an annual, international academy open to musicians, composers and scholars that offers a space for collaboration, encounters and educational purposes. The Atlas Lab includes lectures and seminars by ensemble members and guest professors, workshops for the creation of a new intertraditional contemporary repertoire, masterclasses for instrumentalists and performances and demonstrations of various instruments. During the week of Atlas Lab, composers have the possibility to work alongside musicians to realize and elaborate on sonic ideas. One of the principal objectives of the Atlas Lab is the creation of a virtual library with a comprehensive audiovisual collection of information on non-Western instruments, which can subsequently be utilized by composers and contribute to their stronger implication in the canon of contemporary music. ${ }^{24}$

Whereas the Asian Art Ensemble tries to pass beyond traditions and discover the possibilities of sound creation of the instruments, Atlas' way of treating musical diversity within one ensemble can be categorized as an inspirational network that preserves the variety of traditions and fosters a way of cross-pollination focusing on revealing similarities and differences, finding ways of combining tradition by composition practices. 


\section{Omnibus Ensemble (Tashkent, Uzbekistan)}

At the time of its founding in 2004 by composer and conductor Artyom Kim from Tashkent in Uzbekistan, the Omnibus Ensemble was the first ensemble for contemporary music in Central Asia. Inspired by the idea of playing and promoting the large spectrum of contemporary Western music in their region, an initial group of 40 musicians from Tashkent's Conservatory started the ensemble, which includes traditional Uzbek along with Western instruments. Since its beginnings, the number of musicians has declined to a group of six, ${ }^{25}$ who - besides their involvement with national or international orchestras, universities or as soloists - are devoted to the idea of transcultural musicmaking and research. The repertoire of the ensemble includes masterpieces of the zoth and 21st centuries, as well as a wide range of musical sub-genres that rarely or never have been played in Uzbekistan. Omnibus has thus far been leading in the performance, promotion and research of new music in Central Asia and it functions as an initiator for diverse events and projects devoted to the practical and theoretical confrontation and consolidation of various art forms, as well as the connection between elements of Western music and Uzbek traditions.

Since we were the only contemporary music ensemble for the first 15 years in Central Asia, we had the artistic pressure of consciously presenting any kind of musical genre, from American minimalist music, European classics, preexisting works from jazz, rock, avant-garde and multimedia productions and collaborations with video, choreographers, dancers and finally our own compositions. The idea was not only to make music, but to collaborate with national and international guests and realize cultural or even political events. It was never our goal to form a multicultural ensemble, it just happened naturally because some of our classmates from the Tashkent Conservatory wanted to participate with the Omnibus Ensemble and only played traditional Uzbek instruments. So we needed to think about how to include them and therefore started to study scales, structures, similarities and differences of structural concepts of the different traditions. When you study them deeply enough, you understand the similarities and hear how to combine them. Our experiences show that brilliant theoretical concepts do not necessarily lead to a practicable result. It rather depends on right proportions, balance, equilibrium, artistic taste and the professional and artistic level or talent of those who are doing it. It is easy and natural to play with different instruments, when you have done it for 25 years. $^{26}$

With its involvement with the renowned Ilkhom theatre in Tashkent, ${ }^{27}$ one of the oldest independent theatres in Central Asia, along with international and interdisciplinary festivals for music and visual arts in Tashkent, Omnibus works in favor of the creation of an internationally known Uzbek contemporary art scene.
25. The musicians of Omnibus are: Sukhrob Nazimov (oboe, production of videos for artistic and promotional purposes, management), Jakhongir Shukur (Uzbek sato and other folk instruments, composition, assistance to the artistic direction, assistant conductor, leader of a research project on traditional Uzbek music) Ali Kabdurakhmanov (percussion), Sofia Levchenko (violin, international relations and cooperations), Ravshan Tokhtamishev (chang, leader of a theory-based research project on ornamentation in Uzbek traditional music), Sandjar Nafikov (keyboard, leader of a research project on structures of rhythmical scales).

26. Artyom Kim interviewed by the author via Skype on December 20, 2016.

27. http://ilkhom.com/en/ (consulted on December 15, 2017). 
With the Omnibus Laboratory, since 2005, the ensemble has organized an annual forum with masterclasses held by well-known composers and instrumentalists from Europe and the USA, offering young composers from Tashkent a platform and the opportunity to get to know the currants of contemporary music and being encouraged to evolve new musical styles including Uzbek traditional instruments and compositional techniques.

One of Omnibus' main fields of research projects - called Makomat - is focused on maqoms, a distinctive classical form of Uzbek traditional composition, with an ancient form of notation and micro-chromatic tunings and scales that are combined to cyclic macro-structures. Omnibus developed a modern multi-leveled system that provides the basis of a research concept to generate a profound understanding of the microtonal scales, collecting and archiving audio material of old maqoms, decoding and modernizing the ancient forms of notation and developing new tools to adapt those scales in the modern musical environment.

Omnibus' research- and process-oriented approach towards the crossing of musical traditions and their use in music also manifests in their way of making music and how they developed as an ensemble throughout the years. As a means of common decision-making within the ensemble, Kim developed the composition method of collective resonance composing:

Throughout the last years we preferred to play music composed by ourselves. Our interest is orientated towards the phenomena of the creative processes as a collective and rarely towards the final results of the concerts. Part of our approach is the use of a specific method that I invented, called the method of collective resonance composition. It describes a structured system for creative processes and collective artistic choices. In our rehearsals we apply certain techniques and algorithms such as lists of actions, which are being executed and repeated until we create a specific chemistry. It can be compared to processes of crystallization or even a car junk, where magnets pull certain metals out of unnecessary elements. Through the repetition of this structured process, you get the metal - or musical idea - you want, without defining the author. It is more comparable to the idea of resonance, in which one single idea starts to resonate in the moment within a group or collective. ${ }^{28}$

The method offers specific mechanisms for managing the creative process - both individual and collective - at all stages, from the emergence of the original idea to the structural completion of the artwork.

The category of Omnibus' approach towards transcultural music-making is based on the creation of a contemporary national Uzbek music, which on the one hand affiliates with the concepts of Western avant-garde, but on the other 
hand - and due to its work with ancient musical traditions that date back to a pre-Soviet era - also works as a political means of demarcation.

\section{Hezarfen Ensemble (Istanbul, Turkey)}

The Turkish Hezarfen Ensemble was founded in 2010 in Istanbul as the first professional ensemble for contemporary music performance in Turkey. Initiated by the American composer Michael Ellison and German viola player Ulrich Merten, ${ }^{29}$ the Hezarfen Ensemble integrates well-established Turkish musicians playing Western instruments. ${ }^{30}$ One of the ensemble's goals is to proliferate the diversity of Western classical music in Turkey and collaborate with internationally known composers, conductors and musicians playing concerts and offering workshops and masterclasses for Turkish instrumentalists and composers. The Hezarfen Ensemble establishes a platform for international composers to perform their music in Turkey and to give Turkish composers the option to have their music played by a Turkish ensemble.

Beyond this, one of the main aspects is to encourage the development of a Turkish contemporary classical music scene and emphasize the rich instrumentation of the various Turkish musical traditions. Within its diverse projects, Hezarfen's core musicians facilitate artistic and musical encounters and transtraditional exchanges and collaborate with Turkish instrumentalists playing traditional instruments. Therefore, one particularity is the complexity of Turkish musical traditions that range from the theorized, classical Ottoman art music türk sanat müziğ $i$ to the various folkloristic traditions of halk müziğ $i$, both differing in regard to their sonorities and instrumentation. By means of commissioned pieces, the ensemble raises awareness of the instruments of their own culture and assigns Turkish composers to combine the sonorities of the different Turkish musical traditions using Western, classical Turkish instruments such as kanun, ney or kemence, as well as folkloristic instruments such as baglama or duduk.

The intention of our project aims towards two directions: On the one hand we want to enhance the musicians of Hezarfen and the assigned composers to get a deeper insight into traditional makam music of Turkey and on the other hand we challenge the classical Turkish instrumentalist to learn how to play in an ensemble with a conductor, and discover their own instruments using extended techniques or tuning systems. ${ }^{31}$

According to Ellison, the purpose of Hezarfen's hybridity is to be able to cope and play with different levels of knowledge and musical styles and present a platform to other composers and musicians and musicologists that they can use and work with.
29. Both founders were living in Turkey for many years and have been devoted to playing and research on traditional music in Turkey for many years.

30. Michael Ellison, (composition), Ulrich Mertin (viola), Özcan Ulucan (viola), Müge Hendekli (piano), Amy Salsgiver (percussion), Gökhan Ba CI (cello), Cem Önertürk (cello), Nusret Ispir (clarinet), Nilay Sancar (violin), Ozan Tunca (cello).

31. Michael Ellison interviewed by the author via Skype on May 5, 2017. 
32. Ulrich Merten interviewed by the author via Skype on May 5, 2017.

33. The project "Beyond East and West: Developing and Documenting and Evolving Transcultural Practice" is funded by the European Research Council - Consolidator Grant and takes place from 2015-2020. Team of researchers: Michael Ellison, Simon Jones, Robert Reigle, Amanda Bayley, Argun Çakır, Neal Farwell, Emma Hornby and located at the Centre for Advanced Studies in Music of the Istanbul Technical University, https://www.beyondeastandwest.org (consulted on October 30, 2017).

34. Michael Ellison interviewed by the author via Skype on May 5, 2017.

35. Ibid.
One of the main aspects is to emphasize an actual creative process that leads to new sonic possibilities. Instead of separating Eastern and Western musicians, we want to encourage the Turkish instrumentalist with a background in oral traditions to learn occidental notation and to play with Western musicians. At the same time we train Western musicians and composers to listen deeply to the Turkish makam music to get an insight into its conceptual structures and find ways of adapting them to their own instruments. With our underlying concept of transcultural music-making we want to respect and preserve traditions but also be drawing from them and challenge the musicians to break down existing conceptual and practical barriers and foster new sonorities. ${ }^{32}$

Since 2015, the efforts of the transcultural music-making in Turkey have merged into a funded project for artistic research ${ }^{33}$ that aims to enable musicians, composers and musicologists to develop new ways of notation and sound configuration, as well as extending timbral possibilities and tuning systems and forms of musical collaboration. The planned outcomes include the publication of books and articles on orchestration and notation, as well as the creation of an online information platform with introduction videos and tutorials for Turkish traditional instruments. As Ellison claims:

the purpose of the research project, is to solve the problems regarding different approaches towards orality versus notations or different tuning systems and on the other hand to train interested Western ensembles to open up towards playing microtonal music. Facing the high complexity of each tradition, the biggest challenge of the project is to find the right angle of narrowing it down and make it accessible without neglecting important aspects. ${ }^{34}$

According to Ellison, one of the project's difficulties lies in defining rules and agreeing on the framework of the experimentation, namely installing European standards in the Turkish society, with a basic democratic ensemble structure, including rights and duties and being able to find musicians who have the mastery of playing their instruments while being open towards the idea of the long-term commitment towards the creation of a new music.

With its approach, Hezarfen makes an attempt to create an own Turkish identity, positioning a specific musical voice in between musical worlds. It reaches out towards classical Western music and the current trends of Western contemporary music as well as interweaving traditional differences that are internal to one culture.

Turkish traditions are very desparate and with our work we try to establish forms of communication between musicians from different cultures. We want to be able to be crossing bridges but at the same times we have to build a fundamental from both sides. ${ }^{35}$ 
The five presented transcultural ensembles offer an insight into the different approaches concerning how the use of traditions within the process of creating contemporary music is implemented in functions beyond the pure sonic outcome. Most of the described ensembles face similar difficulties on a conceptual, practical and organizational levels, which they resolve in different manners.

Both Hezarfen and Omnibus are pioneers of contemporary classical music in their region and provide not only a platform for international encounters - enabling the process of affiliation into a Western avant-garde - but foremost a possibility for local composers and musicians to become educated in both classical Western and local traditions. By virtue of their initiatives of research-based projects on different strands of local traditional music within their regions, they revitalize the use of ancient traditions - as in the example of Hezarfen and their attempt to mediate between musical folkloristic traditions and the high art classical Ottoman traditions - while turning it into a method of demarcation from Western music and the construction of a new form of national identification.

By comparison, the Asian Art Ensemble provides a transnational podium in which musicians as well as commissioned composers from different Asian and European countries elaborate the sonic qualities of original Asian instruments and combine them with contemporary composition strategies while aiming to expand the notions of existing musical idioms and traditions.

In opposition, Atlas Ensemble connects musicians from across the world and by applying educational measures they establish musical strategies for cultural cross-pollination and the extension of sonic possibilities, while maintaining the various traditions.

In the latter case, Windstreken Ensemble focuses on the ensemble's internal structure and its continuous progress within the same set of persons, who collectively - and depending on personal capacities - decide on the aesthetic direction of the ensemble.

The presented examples have shown that by offering educational strategies and virtually accessible tutorials, most of the ensembles aim towards a sustainable change of musical perception, as well as enhancing transnational collaborations that reflect on the state of traditions that are the opposite of static, but highly formable and influenced by circumstances.

Nonetheless and despite their openness to different cultures and the elaboration of new ways of transcultural music-making, one of the risks of the described approaches, rests in the subsumption of concepts into a certain Eurological and Eurocentric framework for the encounters with musicians 
from other cultures, which can result in reproaches of cultural appropriation. In most cases - as shown with the Hezarfen Ensemble in Turkey, which is led by two non-Turkish musicians from Germany and the USA - the ensembles are based on the initiative of male musicians originating from or living in Western countries, that offer not only the monetary basis, but also the conceptual strategies for the representation of different cultures. The resulting hierarchy including possible imbalance or asymmetry of power structures and their impact on the musical outcome need to be reviewed cautiously.

In regard to this, a future study could examine the actual musical pieces in order to detect in what sense the imagination of Western music and those of traditions, including its notions of exoticism and orientalism are transported within the music, and whether traditions can effectively co-exist and can create a global contemporary art music that circumvents all cultural differences.

\section{B I B L I O G RAPHY}

BAyley, Amanda and Dutrio, Chartwell (2016), "Developing dialogues in intercultural musicmaking” in Burnard, Mackinlay, and Powell (dir.), The Routledge international handbook of intercultural arts research, Routledge international handbooks of education, Routledge, p. $391-403$.

Biddle, Ian and Knights, Vanessa (dir.) (2007), Music, National Identity and the Politics of Location: Between the Global and the Local, Aldershot, England, Ashgate Popular and Folk Music Series.

Bohlman, Philip V. (dir.) (2013), The Cambridge History of World Music, Cambridge, Cambridge University Press.

Born, Georgina and Hesmondhalgh, David (2000), "Introduction: On Difference, Representation, and Appropriation in Music," in Georgina Born and David Hesmondhalgh (dir.), Western Music and its Others. Difference, Representation, and Appropriation in Music, Berkeley, Los Angeles, London, University of California Press, p. 1-58.

Cook, Nicholas (2013), “Western Music As World Music," in Philip Bohlman (dir.), The Cambridge History of World Music, Cambridge, Cambridge University Press.

Corbett, John (2000), "Experimental Oriental: New Music and Other Others," in Georgina Born and David Hesmondhalgh (dir.), Western Music and its Others. Difference, Representation, and Appropriation in Music, Berkeley, Los Angeles, University of California Press, p. 163-186.

El-Ghadban, Yara (2009), "Facing the Music: Rituals of Belonging and Recognition in Contemporary Western Art Music," American Ethnologist, vol. 36, n 1, p. 140-160.

Frith, Simon (1996), "Music and Identity," in Stuart Hall and Paul du Gay (dir.), Questions of Cultural Identity, London, United Kingdom, SAGE Publications Ltd. p. 108-125.

Hall, Stuart and Du GaY, Paul (dir.) (2011), Questions of Cultural Identity, London, United Kingdom, SAGE Publications Ltd.

NetTL, Bruno (1998), In the course of performance: studies in the world of musical improvisation, Chicago, University of Chicago Press. 
Östersjö, Stefan et NGuYẼN, Thanh Thủy (2007), "Traditions in transformation: the function of openness in the interaction between musicians," in Stefan Östersjö and Henrik Frisk (dir.), (Re)thinking Improvisation: Artistic Explorations and Conceptual Writing, Malmö, Lund University.

STоскеs, Martin (1994), Ethnicity, identity and music: the musical construction of place, Oxford, Berg.

TAYlor, Timothy (2007), Beyond exoticism. Western music and the world, London, Duke University Press.

Utz, Christian (2013), "Erfundene Traditionen und multiple Identitäten," Österreichische Musikzeitschrift, vol. 68, no 4, p. 51-62.

Utz, Christian (2014), Komponieren im Kontext der Globalisierung: Perspektiven für eine Musikgeschichte des 20. und 21. Jahrhunderts, Bielefeld, Transcript-Verlag.

\section{INTERNET LINKS}

Bhagwati, Sandeep, (2013) "Comprovisation - Concepts and techniques," in Signale Graz http://signale.kug.ac.at/signale-graz/konzerte/o111.html (consulted on October 30, 2017).

Asian Art Ensemble: www.asianart-ensemble.com (consulted on October 30, 2017.

Atlas Ensemble: www.atlasensemble.nl/ensemblemembers.html (consulted on October zo, 2017).

Hezarfen Ensemble: www.hezarfenensemble.com (consulted on October 30, 2017).

Omnibus Ensemble: www.omnib us-ensemble.asia (consulted on October 30, 2017).

Windstreken Ensemble: https://windstreken.wordpress.com (consulted on October 30, 2017). 